\title{
A letra da verdade
}

EUGÊNIO BUCCI ${ }^{I}$

$\mathrm{E}$

M A instância da letra no inconsciente, o psicanalista francês Jacques Lacan (1996, p.225) lança um conceito providencial: "Nós designamos por letra esse suporte material que o discurso concreto toma emprestado à linguagem". Claro que, em se tratando de quem se trata, o sentido escapa. "Desliza”, dirão os lacanianos. O que não nos impede de tentar articulá-lo. A frase nos ajuda a lembrar que a letra não é abstração: é matéria. Nesse ponto, o agitador cultural Lacan parece ecoar de modo inadvertido, muito embora brilhante (o inconsciente opaco, às vezes, é brilhante), o pressuposto do linguista Bakhtin, que não era o seu predileto. Bakhtin (1997, p.31), anterior a Lacan, não abria mão da condição do signo como suporte material.

Todo fenômeno que funciona como signo ideológico tem uma encarnação material, seja como som, como massa física, como cor, como movimento do corpo ou como outra coisa qualquer. Nesse sentido, a realidade do signo é totalmente objetiva e, portanto, passível de um estudo metodologicamente unitário e objetivo.

Lacan não diz exatamente o mesmo. Diz quase o mesmo, embora olhando para um objeto outro. Procura, em vez do signo, a letra irredutível, a letra como o tijolo essencial (o que teria sido átomo para Demócrito) de que se servem as construções a que chamamos palavras, signos ou, eventualmente, "signos ideológicos”. Esses tijolos estão nos textos, por certo, assim como estão nas coisas corpóreas. Isso mesmo. Para Bakhtin, uma palavra pode ser um signo ideológico - e uma enxada caída sobre um canteiro também opera como um signo quando olhamos para ela. As coisas todas que permeiam o campo do visível - e do legível - atuam como signos ideológicos. Tudo o que aí está - uma árvore cercada de ruas asfálticas por todos os lados ou esta sucessão de sílabas mal alinhadas deste meu texto, meu contexto, meu discurso - cumpre o papel de signo.

A realidade é discursiva. O cenário a que se dá o nome de realidade pode ser esfumaçado, pode ser nuvem, pode ser direto, óbvio, chapado ou fugidio, não importa: é sempre ele a realidade. Tecida de fragmentos materiais, que suportam o discurso que fala a partir de seus signos, ela pode ser até realidade material, sem que por isso deixe de ser discursiva. O seu lastro da letra, qual seja, “o suporte material que o discurso toma emprestado à linguagem”.

Isso posto, perguntemo-nos sobre as letras que escrevem a palavra "verdade" no trabalho realizado pela Comissão Nacional da Verdade (CNV). O suporte material seriam as provas materiais arroladas, recuperadas e reafirmadas em novo contexto? Ou o suporte material são as letras de que se servem as palavras do discurso da verdade? 
Penso que podemos dizer sim às duas indagações. Penso ainda que as duas respostas não se contradizem, em nenhum plano. O primeiro sim reforça o segundo sim. Cuidemos então de especular acerca das duas indagações. É para isto que serve este artigo - ou esta "resenha", se o leitor assim o preferir. O relatório final da CNV, agora lançado em livro, reescreve o discurso oficial do Brasil sobre si mesmo - reinscreve letras que estavam sepultadas (ou insepultas) no passado para restabelecer a fala de nada menos que o Estado brasileiro. O relatório muda a realidade do Brasil, mas isso se dá e se dará de modo um tanto arrastado, como veremos agora.

A Comissão Nacional da Verdade foi oficialmente instalada em 16 de maio de 2012, em obediência à Lei n.12528/2011, com a finalidade de apurar graves violações de direitos humanos ocorridas entre 18 de setembro de 1946 e 5 de outubro de 1988, com sete integrantes (Cláudio Fonteles, Gilson Dipp, José Carlos Dias, João Paulo Cavalcanti Filho, Maria Rita Kehl, Paulo Sérgio Pinheiro e Rosa Maria Cardoso da Cunha). Foi empossada num ato solene que contou com a participação da presidente da República, Dilma Rousseff, e dos ex-presidentes Fernando Collor, José Sarney, Fernando Henrique Cardoso e Luiz Inácio Lula da Silva. A cerimônia reforçou o caráter de Estado, mais do que de governo, da comissão instalada ali. Era um ato de governo, sem dúvida, que aspirava, porém, uma dimensão menos partidária, menos conjuntural e mais permanente.

Em dezembro de 2013, o mandato da CNV foi prorrogado até dezembro de 2014 pela medida provisória n.632. No dia 10 de dezembro de 2014, o então coordenador da Comissão Nacional da Verdade, Pedro Dallari (que passara a integrar o grupo em setembro de 2013, em substituição a Cláudio Fontelles), ladeado por seus pares, entregou o relatório final à presidente da República, numa cerimônia discreta no Palácio do Planalto. Com 4.328 páginas, o documento apontou 377 responsáveis por tortura e assassinatos e outras graves violações dos direitos humanos durante o período investigado, de 1946 a 1985 (quase todos esses crimes foram praticados na ditadura militar, entre 1964 e 1985). Ao final, o relatório apresentou 29 recomendações - como a desmilitarização da Polícia Militar - e defendeu a punição para agentes do Estado que praticaram as violações constatadas, como detenções ilegais, execuções, desaparecimentos forçados e ocultação de cadáveres, além da tortura. Era, com efeito, um resultado bem pouco "diplomático", bem pouco festivo. Difícil.

Depois disso, a recepção oficial dos documentos pelo governo atrasou bastante. Somente no dia 29 de setembro de 2015 - nove meses e 19 dias depois, portanto - é que veio a oficialização, por meio de uma portaria interministerial (n.1.321-A), publicada no Diário Oficial uma semana mais tarde. ${ }^{1}$ A portaria, assinada apenas por ministros (da Casa Civil, da Justiça, da Secretaria Geral da 
Presidência da República e da Secretaria de Direitos Humanos da Presidência da República), e não pela chefe de Estado, rebaixou em um grau o tratamento dado ao tema. Em síntese, ao menos no plano da simbologia de que se cercou, a CNV passou por um desprestígio entre o ato de sua instalação e o seu desfecho.

O lado bom das coisas é que, antes mesmo de o Estado brasileiro dignar-se a declarar recebidos os três volumes do relatório, eles foram publicados. Em formato de papel ofício, densos e pesados, o relatório não deixa dúvida quanto à sua materialidade. São mais que suportes materiais da verdade. São mais que pequenos tijolos dos quais são feitos os signos; são seis tijolaços de letras miúdas. São seis porque os três volumes estão organizados em seis tomos: dois para o volume 1 , um para o volume 2 e três para o volume 3 . As 4.328 páginas originais (entregues à presidente da República) foram reformatadas e agora se limitam a 3.400 .

A tiragem não é grandiosa. Foram impressos dois mil exemplares de cada um dos seis tomos, que seguiram já no primeiro semestre de 2015 para bibliotecas de universidades brasileiras (e algumas do exterior). O texto integral também está acessível no site da CNV (www.cnv.gov.br).

A Impressa Nacional, responsável pela versão impressa, inscreveu o documento para o Prêmio Jabuti e, em outubro, o trabalho consta na lista dos finalistas (categoria Ciências Humanas) da Câmara Brasileira do Livro, que confere anualmente esse que é o mais prestigioso reconhecimento das letras no Brasil. É merecido. As letras inscritas no relatório carregam uma verdade complexa e doída, que só se tornou documento de Estado graças a um esforço de investigação (e também político) praticamente sem paralelos. Foram ouvidas cerca de 1.200 testemunhas. A pesquisa foi apoiada por uma equipe integrada por servidores nomeados pela CNV e outros cedidos por órgãos da administração pública, além de especialistas contratados por meio do PNUD. A cooperação de outras comissões da verdade de universidades e outras unidades federativas também é registrada no relatório.

Em todos os aspectos, as dimensões do trabalho impressionam. Não surpreende que não seja de fácil assimilação pela rotina institucional do Estado brasileiro. Quanto a isso, até mesmo os recuos do governo federal, que foi retumbante na largada e esquivo na chegada, atestam as arestas vivas dessas letras. A falta de jeito com que o mesmo Poder Executivo que encomendou o trabalho procurou aplainar-lhe o perfil na fase de sua conclusão pode ser lido como um atestado da dureza da verdade encerrada nessas letras. A mesma Presidência da República que se pôs em trajes de gala no momento de formular a encomenda (a pergunta) dispensou a pompa no momento de receber o trabalho pronto (a resposta). O suporte material que veio à tona talvez tenha sido mais problemático do que consagrador. As provas materiais (letras materiais), timbradas em páginas oficiais, desorganizaram a etiqueta do consenso precário. A letra da verdade ficou sem abrigo, mas ficou posta. 
É interessante. O relatório da CNV recebeu mais homenagens fora do que dentro do Brasil. Citemos as duas mais recentes. No dia 15 de outubro de 2015, o coordenador Pedro Dallari, diretor do Instituto de Relações Internacionais da Universidade de São Paulo, foi agraciado, por seu trabalho na Comissão Nacional da Verdade, com o Prêmio Iberoamericano ASICOM-Universidad de Oviedo, outorgado anualmente apela Asociación Iberoamericana de la Comunicación (ASICOM) e pela Universidade de Oviedo. Dois dias antes, na Universidade de Salamanca, compareceu à inauguração de uma exposição sobre os trabalhos da Comissão Nacional da Verdade do Brasil, produzida pelo CEB-USAL e pelo Arquivo Nacional brasileiro.

No Brasil, a trava predomina, embora surjam, aqui e ali, boas notícias geradas pela extensa pesquisa empreendida pela CNV. No dia primeiro de novembro, por exemplo, um domingo, o diário $O$ Estado de S. Paulo publicou, no alto de sua primeira página, uma manchete animadora (mas igualmente difícil): "Volks busca reparar apoio à repressão na ditadura". A reportagem de Marcelo Godoy e Cleide Silva narra um fato que é consequência direta do relatório da CNV. Segundo informam em primeira mão os dois repórteres, a Volkswagen começou a negociar judicialmente com o Ministério Público Federal (MPF) "uma reparação por ter financiado ou participado ativamente da repressão à oposição política e ao movimento operário durante a ditadura militar no Brasil". A base da ação proposta pelo MPF é justamente a investigação conduzida pela Comissão Nacional da Verdade, cujos efeitos positivos existem - seguem trilhas tortuosas e acidentadas, mas aos poucos afloram.

Houve quem dissesse que o relatório não traz "novidades". À primeira vista, não trouxe mesmo. O número de mortos e desaparecidos não é "novidade": 434. Desses, 224 foram comprovadamente assassinados e 210 foram "desaparecidos". No volume 3, páginas 25 a 29, o leitor encontra explicações sobre referências metodológicas adotadas para que se chegasse a essa quantificação. $\mathrm{O}$ relatório reconhece que o contingente pode ser maior (para se ter uma ideia dessas estimativas, o texto sobre índios, constante do volume 2, páginas 203 a 262, elaborado sob a responsabilidade de Maria Rita Kehl, fala em sete mil vítimas), mas, na contagem constante do primeiro volume, assinada por todos os seus integrantes, a CNV arrolou apenas os casos que foram individual e integralmente comprovados, dentro do contexto das violações dos direitos humanos praticadas por agentes do Estado.

A “novidade”, porém, existe. Ela é real. É material. Não está no anúncio de nomes de mortos e desaparecidos. Há, sim, uma série de demonstrações pormenorizadas com descrições inéditas de procedimentos, como sobre os "desaparecimentos" do deputado socialista Rubens Paiva (páginas 561 e seguintes do primeiro tomo do primeiro volume) e do militante Stuart Edgard Angel Jones (páginas 571 e seguintes), ambos de $1971,{ }^{2}$ mas não é aí que repousa a "novidade". Levantamentos anteriores já tinham dado conta dessas listas, em boa parte, como o livro publicado pelo grupo Tortura Nunca Mais, e os trabalhos da 
Comissão de Anistia e a Comissão de Mortos e Desaparecidos Políticos, criada no governo Fernando Henrique Cardoso, que deu início ao pagamento de indenizações aos que sofreram perseguições políticas e aos seus familiares. A novidade que mais conta pode ser apontada em dois aspectos centrais.

O primeiro é a responsabilização direta e indireta de nomes próprios pelas graves violações de direitos humanos durante a ditadura militar. São 377 nomes (páginas 841 e seguintes do segundo tomo do primeiro volume), num rol de nomes encabeçado por militares que ocuparam a Presidência da República. Sabe-se, hoje, que a decisão de nomeá-los não foi uma trivialidade dentro da CNV. Houve hesitações. Mas, como a própria lei que a instituiu a incumbiu de apontar responsabilidades (inciso II do artigo $3^{\circ}$ da Lei n.12.528/2011), o bom senso e a coragem prevaleceram.

O segundo aspecto central que realmente descortina uma novidade no relatório é a visão de conjunto que emerge das milhares de páginas repletas de minúcias documentadas. Para aqueles que sempre repetiram que a ditadura brasileira teria sido "branda" (pois o número de mortos é menor do que o verificado nas ditaduras militares da Argentina e do Chile), o trabalho demonstra que a repressão no Brasil atuou como uma indústria bem planejada. Desde os trabalhos do grupo Tortura Nunca Mais já se sabia que cerca de vinte mil pessoas foram torturadas, mais de sete mil foram julgadas pela Justiça Militar e, dessas, nada menos que 2.800 foram condenadas. Agora, nas páginas do relatório da $\mathrm{CNV}$, descortinam-se as linhas de comando estatais e as instalações físicas de um aparato repressivo meticuloso e seletivo, que foi certeiro e frio em seus assassinatos: matou criteriosamente os líderes das organizações de esquerda.

As relações entre essas engrenagens (tão eficientes quanto desumanas) e as orientações vindas dos militares dos Estados Unidos também resultam claras. Como resumiu Pedro Dallari, em entrevista ao semanário Voces, do Uruguai, "a base [dessas orientações] era a Academia de Panamá, a Escola das Américas, que fazia formação". Nessa matéria, continua ele, "a CNV avançou muito em mostrar os nomes, a rotina, as instruções de tortura" (Voces, 2015). Em outra entrevista, o coordenador da CNV retoma o assunto, e seu depoimento enfático transmite a magnitude dessa revelação:

O que me marcou muito nessa investigação, foi justamente a percepção de quão organizada foi a repressão, ou seja, de que realmente as graves violações de direitos humanos não foram fruto de alguns militares descontrolados, mas foram fruto de uma ação organizada do Estado, com cadeias de comando bem estabelecidas. Eu não tinha clara essa percepção antes, e passei a ter em função da investigação da Comissão Nacional da Verdade. (Revista de Estudios Brasileños, 2015)

Em suma, o que o relatório traz de novo, acima de tudo, é inscrever a letra da verdade no Diário Oficial da União. De algum modo, essa letra ainda era prisioneira do submundo da ditadura, dos tais "porões". Agora, ela pertence ao público. Trata-se de uma proeza que já começa a acarretar mudanças, ainda que vagarosas. 
Por fim, quase que como um post scriptum, caberia fazer uma solicitação. Os seis tomos do relatório final, em letra miúda, oferecem um inestimável material de pesquisa num documento histórico de relevo. A consulta, porém, não é simples. Se o relatório é, como é, uma grande obra de referência, o modo como está organizado ainda deixa a desejar. Seria oportuna a publicação de um livro em linguagem jornalística, que desse conta de condensar e explicar as principais conclusões para o leitor não especializado.

Também no site (cnv.org.br), que oferece os três volumes para download em PDF, o sistema de busca não soube se beneficiar de recursos mais amigáveis hoje disponíveis no ambiente digital. Na internet, os volumes do relatório ainda esperam por uma navegabilidade mais acessível, com mecanismos de busca mais ágeis e mais abertura para cruzamentos de dados.

Isso ajudaria na difusão do legado monumental da CNV para o grande público. Trata-se de uma tarefa prioritária. Se não sensibilizar o grande público, esse trabalho digno de todo o nosso reconhecimento ainda estará longe de tocar o coração do Brasil. A instância da letra nas profundezas do inconsciente (o fundo escuro do coração) só ganha o estatuto de suporte material quando conforma uma realidade renovada. $\mathrm{Ou}$, em termos mais burocráticos, quando se torna verdadeiramente de domínio público. Quanto a isso, ainda estamos no meio do caminho.

\section{Notas}

1 Publicado no Diário Oficial da União, de 7 de outubro de 2015, Seção 1, p.5.

2 Vale consultar, também, as biografias dos mortos e desaparecidos no terceiro tomo do Volume III.

\section{Referências}

BAKHTIN, M. Marxismo e filosofia da linguagem. 8.ed. São Paulo: Hucitec, 1997.

BRASIL. Comissão Nacional da Verdade. Relatório / Comissão Nacional da Verdade. Volume I - Relatório (tomos l e 2), Volume II - Textos temáticos (tomo único) e Volume III - Mortos e desaparecidos políticos (tomos 1, 2 e 3). Brasília: CNV, 2014.

LACAN, J. A instância da Letra no Inconsciente. In: Escritos, 4.ed. São Paulo: Perspectiva, 996.

REVISTA DE ESTUDIOS BRASILEÑOS. Entrevista a Ignacio Berdugo Gómez de la Torre Universidad Salamanca - USP. v.2, n.3 p.166-84, 2015.

VOCES. Entrevista a Jorge Lauro y Alfredo Garcia. n.463, p.17-20, 5 de março de 2015 .

Eugênio Bucci é professor do Departamento de Jornalismo da Escola de Comunicações e Artes da USP. @ - eugeniobucci@uol.com.br

Recebido em 6.11.2015 e aceito em 10.12.2015.

${ }^{\text {I }}$ Escola de Comunicações e Artes, Universidade de São Paulo. São Paulo/ São Paulo, SP. 